\title{
Polyethylenimine-based theranostic nanoplatform for glioma-targeting single-photon emission computed tomography imaging and anticancer drug delivery
}

Lingzhou Zhao ${ }^{1 \dagger}$, Jingyi Zhu ${ }^{2 \dagger}$, Jiali Gong ${ }^{1 \dagger}$, Ningning Song ${ }^{1}$, Shan Wu ${ }^{1}$, Wenli Qiao ${ }^{1}$, Jiqin Yang ${ }^{3 *}$, Meilin Zhu ${ }^{4^{*}}$ and Jinhua Zhao ${ }^{1 *}$ (1)

\begin{abstract}
Background: Glioma is the deadliest brain cancer in adults because the blood-brain-barrier (BBB) prevents the vast majority of therapeutic drugs from entering into the central nervous system. The development of BBB-penetrating drug delivery systems for glioma therapy still remains a great challenge. In this study, we aimed to design and develop a theranostic nanocomplex with enhanced BBB penetrability and tumor-targeting efficiency for glioma single-photon emission computed tomography (SPECT) imaging and anticancer drug delivery.
\end{abstract}

Results: This multifunctional nanocomplex was manufactured using branched polyethylenimine (PEI) as a template to sequentially conjugate with methoxypolyethylene glycol (mPEG), glioma-targeting peptide chlorotoxin (CTX), and diethylenetriaminepentaacetic acid (DTPA) for ${ }^{99 \mathrm{~m}} \mathrm{Tc}$ radiolabeling on the surface of PEl. After the acetylation of the remaining PEl surface amines using acetic anhydride $\left(\mathrm{Ac}_{2} \mathrm{O}\right)$, the CTX-modified PEI ( $m$ PEI-CTX) was utilized as a carrier to load chemotherapeutic drug doxorubicin (DOX) in its interior cavity. The formed $m P E I-C T X / D O X$ complex had excellent water dispersibility and released DOX in a sustainable and pH-dependent manner; furthermore, it showed targeting specificity and therapeutic effect of DOX toward glioma cells in vitro and in vivo (a subcutaneous tumor mouse model). Owing to the unique biological properties of CTX, the mPEI-CTX/DOX complex was able to cross the BBB and accumulate at the tumor site in an orthotopic rat glioma model. In addition, after efficient radiolabeling of PEI with ${ }^{99 m}$ Tc via DTPA, the ${ }^{99 m}$ Tc-labeled complex could help to visualize the drug accumulation in tumors of gliomabearing mice and the drug delivery into the brains of rats through SPECT imaging.

Conclusions: These results indicate the potential of the developed PEI-based nanocomplex in facilitating gliomatargeting SPECT imaging and chemotherapy.

Keywords: Polyethylenimine, Chlorotoxin, Drug delivery, SPECT imaging, Glioma

*Correspondence: qin-yj06@163.com; jay70281@163.com;

zhaojinhua1963@126.com

'Lingzhou Zhao, Jingyi Zhu and Jiali Gong equally contributed to this work

${ }^{1}$ Department of Nuclear Medicine, Shanghai General Hospital, Shanghai

Jiao Tong University School of Medicine, Shanghai 200080, People's

Republic of China

${ }^{3}$ Department of Nuclear Medicine, General Hospital of Ningxia Medical

University, Yinchuan 750004, Ningxia, People's Republic of China

${ }^{4}$ School of Basic Medical Sciences, Ningxia Medical University,

Yinchuan 750004, Ningxia, People's Republic of China

Full list of author information is available at the end of the article

\section{Background}

The diffuse invasion and infiltrative overgrowth of glioma cells lead to the development of irregular and indistinct tumor margins, making surgical resection difficult; consequently, patients with malignant gliomas always have a very poor prognosis $[1,2]$. The special pathological and physiological characteristics of the blood-brain barrier

c) The Author(s) 2020. This article is licensed under a Creative Commons Attribution 4.0 International License, which permits use, sharing, adaptation, distribution and reproduction in any medium or format, as long as you give appropriate credit to the original author(s) and the source, provide a link to the Creative Commons licence, and indicate if changes were made. The images or other third party material in this article are included in the article's Creative Commons licence, unless indicated otherwise in a credit line to the material. If material is not included in the article's Creative Commons licence and your intended use is not permitted by statutory regulation or exceeds the permitted use, you will need to obtain permission directly from the copyright holder. To view a copy of this licence, visit http://creativeco mmons.org/licenses/by/4.0/. The Creative Commons Public Domain Dedication waiver (http://creativecommons.org/publicdomain/ zero/1.0/) applies to the data made available in this article, unless otherwise stated in a credit line to the data. 
(BBB) allow merely a few chemotherapeutic drugs into the brain in the early stage [3]. This strictly limited selection imposes a great challenge on glioma treatment. To overcome this issue, various nanoparticulate platforms have been widely investigated to develop BBB-penetrating delivery systems because of their great clinical potential in cancer diagnosis and treatment [4-6]. These nanoplatforms can be exploited as imaging agents to guide the maximal surgical resection, drug carriers to improve chemotherapy, or theranostic systems to achieve imaging-guided drug delivery and therapy monitoring [7-11].

Although the BBB penetrability of some nanoparticles (NPs) can be improved through specific modification (for example attaching PEG chain or charged/lipophilic groups) [12-14], an active strategy has attracted much more attention $[15,16]$. In this active strategy, NPs are generally modified with targeting molecules such as peptides or antibodies, which help NPs bind to endothelial cells of BBB selectively and traverse into the brain via receptor/transporter-mediated transcytosis [17-19]. In previous studies, some receptors and transporters, including but not limited to transferrin receptor, low density lipoprotein receptor, insulin receptor, nicotinic acetylcholine receptor, amino acid transporter, choline transporter, hexose transporter, and monocarboxylic acid transporter, have been determined to be involved in receptor/transporter-mediated transcytosis across BBB [19-26]. These findings have motivated numerous researchers around the world to focus on the development of novel brain targeting systems for glioma imaging and treatment. Moreover, some promising targets, such as the chloride ion channel, which is overexpressed on glioma cells and involved in multiple malignant features of glioma including proliferation, migration, and apoptosis, also arouse intensive interest [27-30]. As a ligand of the chloride ion channel, chlorotoxin (CTX), a small peptide purified from scorpion venom, has been proven to have the ability to penetrate the BBB and show high affinity binding to glioma cells via chloride ion channel and matrix metalloproteinase 2 [31]. Once bound to the receptors on glioma cell surface, the peptide can be internalized into cells. These unique biological properties of CTX make it a potential targeting agent for glioma diagnosis and therapy [32-34]. Perceiving this, the feasibility of using radionuclide ${ }^{131} \mathrm{I}$ and fluorescent molecule (indocyanine green) labeled CTX molecules for glioma imaging and treatment has been investigated in clinical trials $[35,36]$. Notably, a variety of CTX peptide modified NPs, for instance, CTX-conjugated iron oxides, liposomes, dendrimers, quantum dots, and rare-earth up-conversion NPs, have been studied as potential candidates in this field $[37,38]$. These NPs can not only be used as imaging agents for diagnosis or as drug carriers for treatment, but also as multifunctional systems for theranostic applications. Among these NPs, dendritic polymers such as poly(amidoamine) and polyetherimide (PEI) dendrimers, have been considered as promising templates to construct theranostic nanosystems for various kinds of tumors, including brain cancer $[39,40]$.

In our previous study, we reported CTX-modified dendrimers for glioma imaging and therapy [41]. The developed multifunctional dendrimers exhibited acceptable imaging performance and targeted radionuclide therapy effect, and they could further entrap gold NPs for glioma single-photon emission computed tomography/computed tomography (SPECT/CT) imaging [42]. More importantly, because of the modification of CTX peptide, this kind of dendrimer nanoplatform possesses the ability to cross the BBB and target glioma cells. These results together with the attractive features of CTX facilitated our further investigation of dendrimer-based BBBpenetrating NPs as chemotherapeutic drug carriers for glioma therapy. In addition, compared to the ${ }^{131}$ I used in our previous studies, ${ }^{99 \mathrm{~m}} \mathrm{Tc}$ is a better radionuclide for SPECT imaging, which is associated with a higher imaging resolution because of its physical properties such as nearly pure electron capture decay and low $\gamma$-ray energy $(140 \mathrm{keV})$ [43, 44]. Therefore, in the present study, a BBB-penetrating imaging-guided drug delivery nanosystem was designed and synthesized using branched PEI as the template by encapsulation of doxorubicin (DOX) and conjugation of CTX peptide and radionuclide ${ }^{99 \mathrm{~m}} \mathrm{Tc}$. DOX was encapsulated into the interior cavities by physical interactions, while CTX and ${ }^{99 \mathrm{~m}} \mathrm{Tc}$ were covalently conjugated on the surface of PEI via a PEG chain and bifunctional chelating agent (diethylenetriaminepentaacetic acid, DTPA), respectively. The designed theranostic nanosystem was characterized via different techniques to determine the structure, size, release kinetics, and stability. The targeting specificity and therapeutic efficacy toward glioma cells were evaluated in vitro and in vivo using a subcutaneous glioma tumor model, and the $\mathrm{BBB}$ penetrability was investigated via an intracranial rat model, which could be further visualized after the ${ }^{99 \mathrm{~m}} \mathrm{Tc}$ radiolabeling through SPECT imaging. Therefore, a combination of glioma-specific agent, chemotherapeutic drug, and radionuclide imaging could be a novel strategy for the imaging-guided drug delivery for brain cancer.

\section{Methods \\ Synthesis of PEI.NHAC-DOX-(PEG-CTX)-mPEG-DTPA- ${ }^{99 \mathrm{~m}} T c$}

In this study, the PEI-based theranostic nanosystem was prepared according to protocols reported in the literature [42]. Briefly, reaction of PEI.NH $\mathrm{N}_{2}$ with $m \mathrm{PEG}-\mathrm{COOH}$ led to the formation of PEGylated PEI (PEI.NH $\mathrm{N}_{2}-m \mathrm{PEG}$ ). 
MAL-PEG-SVA was attached to the PEI.NH $\mathrm{N}_{2}-m$ PEG to modify with CTX peptide in the next step. To achieve the CTX modification in a convenient way, an extra cysteine residue was added at its $\mathrm{C}$-terminal, which could react with the maleimide group on the PEI surface to form PEI. $\mathrm{NH}_{2}$-(PEG-CTX)- $m$ PEG. After that, the PEI.NH ${ }_{2}$-(PEGCTX)-mPEG was decorated with DTPA, which is one of the most frequently used bifunctional chelating agent for ${ }^{99 \mathrm{~m}} \mathrm{Tc}$ radiolabeling, and the remaining PEI terminal amines were acetylated using excess $\mathrm{Ac}_{2} \mathrm{O}$. Finally, the PEI.NHAc-DTPA-(PEG-CTX)- $m$ PEG ( $m$ PEI-CTX) was used to encapsulate the anticancer drug DOX, and the synthesized PEI.NHAc-DTPA-(PEG-CTX)-mPEG/DOX ( $m$ PEI-CTX/DOX) complex could be further labeled with ${ }^{99 \mathrm{~m}} \mathrm{Tc}$ using $\mathrm{SnCl}_{2}$ as the reductant. The schematic illustration of the synthetic process is shown in Fig. 1, and the details are provided in supplementary information.

\section{Cytocompatibility and cytotoxicity analysis}

CCK-8 assay was employed to assess the cytocompatibility of $m$ PEI-CTX without DOX and the cell cytotoxicity after DOX encapsulation. For this assay, C6 cells were plated in 96-well plates at a density of 8,000 cells per well and incubated for $24 \mathrm{~h}$. These cells were then treated with $m \mathrm{PEI}-\mathrm{CTX} / \mathrm{DOX}, m \mathrm{PEI} / \mathrm{DOX}$, and free DOX at different DOX concentrations $(0-10 \mu \mathrm{g} / \mathrm{mL})$ or $m$ PEI-CTX and $m$ PEI at different polymer concentrations $(0-100 \mu \mathrm{g} / \mathrm{mL})$ for $24 \mathrm{~h}$ and $48 \mathrm{~h}$, respectively. After washing the cells 3 times with PBS, CCK- 8 solution $(100 \mu \mathrm{L})$ was added to each well, and the cells were cultured for $2 \mathrm{~h}$. The absorbance at $450 \mathrm{~nm}$ was measured using a Varioskan Flash multimode microplate reader (Thermo Fisher Scientific, Waltham, MA, USA).
To test the influence of the complex on the cytoskeleton, $\mathrm{C} 6$ cells were seeded in a 12-well plate at a density of $2 \times 10^{5}$ cells per well. Subsequently, these cells were incubated with $m$ PEI-CTX/DOX, $m$ PEI-CTX, and free DOX at the DOX concentration of $5 \mu \mathrm{g} / \mathrm{mL}$. PBS was set as a negative control. After $24 \mathrm{~h}$, the cytoskeleton was visualized by confocal microscopic imaging using the standard protocols [45].

\section{Confocal laser scanning microscopy (CLSM) and flow cytometry analysis}

Confocal microscopy and flow cytometry analysis were applied to determine the targeting specificity of $m$ PEICTX/DOX in vitro. For confocal microscopy, C6 cells were seeded into each well of 24-well plates at a density of $5 \times 10^{4}$ and cultured for $24 \mathrm{~h}$. The medium was replaced with $1 \mathrm{~mL}$ of fresh medium containing $m$ PEICTX/DOX or $m \mathrm{PEI} / \mathrm{DOX}$ at the DOX concentration of $8 \mu \mathrm{g} / \mathrm{mL}$. PBS was set as a negative control. After $4 \mathrm{~h}$, the cells were rinsed, fixed, counterstained, and observed. For flow cytometry analysis, C6 cells were seeded in a 12-well plate $\left(2 \times 10^{5}\right.$ cells per well $)$ and incubated for $24 \mathrm{~h}$. The C6 cells were treated with $m \mathrm{PEI}-\mathrm{CTX} / \mathrm{DOX}$ and $\mathrm{mPEI} /$ DOX at different DOX concentrations $(0-8 \mu \mathrm{g} / \mathrm{mL})$. After $4 \mathrm{~h}$, the cells were harvested and washed 3 times with PBS, and the fluorescence intensities per 10,000 cells were recorded in the FL1-fluorescence channel using a BD AccuriTM C6 Flow Cytometer (BD Biosciences, Franklin Lakes, NJ, USA).

\section{In vitro SPECT imaging}

In vitro SPECT imaging was used to confirm the cellular uptake of $m$ PEI-CTX/DOX after ${ }^{99 \mathrm{~m}}$ Tc radiolabeling by glioma cells. In brief, C6 cells were seeded in 12-well

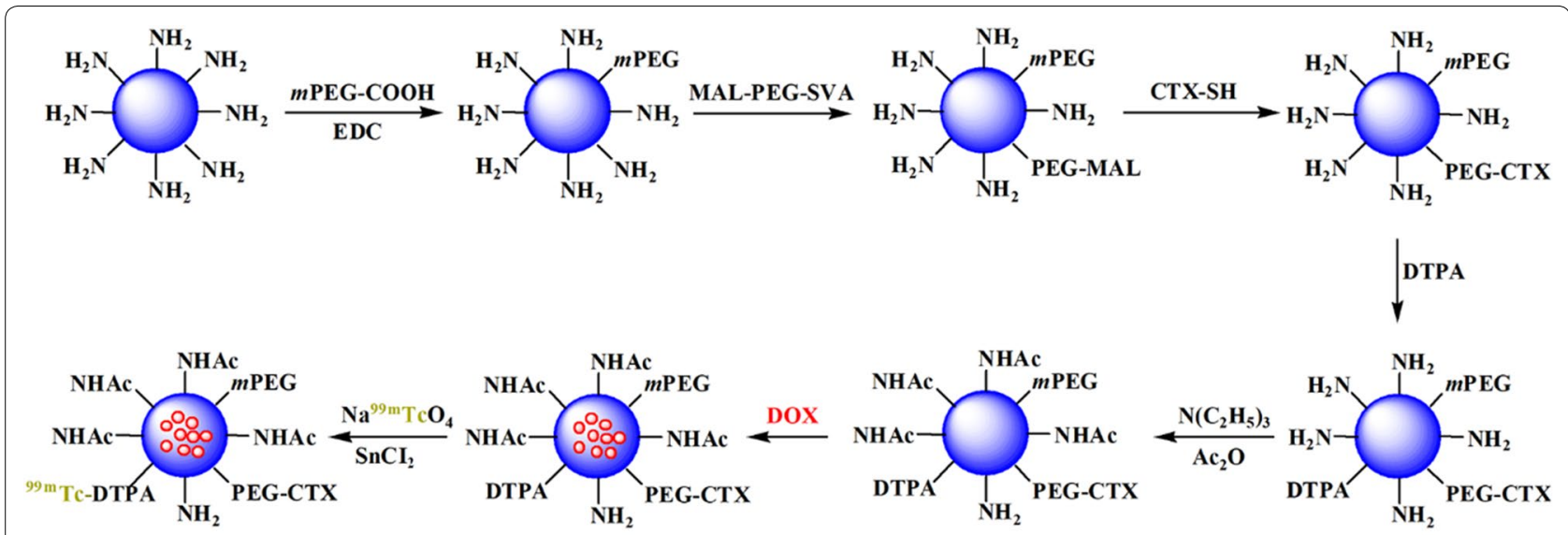


plates at a density of $2 \times 10^{5}$ cells/well. After incubation for $24 \mathrm{~h}$, the culture medium was replaced with $2 \mathrm{~mL}$ of fresh medium containing $m$ PEI-CTX- ${ }^{99 \mathrm{~m}} \mathrm{Tc} / \mathrm{DOX}$ and $m \mathrm{PEI}-$ ${ }^{99 \mathrm{~m}} \mathrm{Tc} / \mathrm{DOX}$ at different radioactivity concentrations (50, 100,200 , and $400 \mu \mathrm{Ci} / \mathrm{mL}$ ). After $4 \mathrm{~h}$ incubation, the cells were harvested and washed 3 times with PBS, centrifuged in $1.5 \mathrm{~mL}$ tubes, and imaged by a SPECT imaging system equipped with Xeleris 2.0 Workstation and low-energy general-purpose collimators (Infinia, Denver, CO).

\section{Targeted SPECT imaging of glioma in tumor model}

Before SPECT imaging in vivo, the mice were divided into targeted and non-targeted groups (6 mice per group) at random. The targeted group was intravenously administrated saline solution containing $m \mathrm{PEI}-\mathrm{CTX}{ }^{-99 \mathrm{~m}} \mathrm{Tc} / \mathrm{DOX}$ $(600 \mu \mathrm{Ci}, 100 \mu \mathrm{L})$, and a same dose of $m$ PEI- ${ }^{99 \mathrm{~m}} \mathrm{Tc} / \mathrm{DOX}$ was injected in the non-targeted group. SPECT images were then captured at $0.5,2,4,6,8$, and $12 \mathrm{~h}$ post-injection. At $12 \mathrm{~h}$ post-injection, one mouse from each group was euthanized, and the tumors and major organs (heart, lung, liver, stomach, spleen, kidneys, soft tissue, and intestines) were collected for analysis of the relative signal intensities.

We subsequently evaluated the therapeutic efficacy of $m$ PEI-CTX/DOX in vivo in the subcutaneous tumor model. Ten days after tumor inoculation, the mice were split randomly into 6 groups (6 mice per group). The mice in each group were sequentially treated with $m \mathrm{PEI}-\mathrm{CTX} /$ DOX, $m$ PEI/DOX, $m$ PEI-CTX, $m$ PEI, free DOX, and saline via intravenous injection at a DOX concentration of $1 \mathrm{mg} / \mathrm{mL}$ in $100 \mu \mathrm{L}$ saline solution. The treatments were then performed every 3 days, accounting for a total of 7 times, and the tumor size and body weight of each mouse were recorded after each treatment. Their relative tumor volumes, body weights, and survival rates were calculated as described in our previous work [45]. After a three-week treatment, the representative mice from these groups were sacrificed to harvest the tumors and major organs including the heart, liver, spleen, lung, and kidneys. The hematoxylin and eosin (HE) and terminal deoxynucleotidyl transferase dUTP nick end labeling (TUNEL) assay were performed according to the standard protocols to investigate the potential toxicity of $m$ PEI-CTX/DOX in vivo [45].

\section{Targeted SPECT imaging of glioma in an orthotopic glioma rat model}

To verify the $\mathrm{BBB}$ penetrability and tumor-targeting efficiency of $m$ PEI-CTX/DOX, an orthotopic glioma rat model was established according to the method described previously [42]. Fourteen days later, twelve rats were equally divided into two groups and injected with $m$ PEI-CTX- ${ }^{-99 \mathrm{~m}} \mathrm{Tc} / \mathrm{DOX}$ and $m$ PEI ${ }^{-99 \mathrm{~m}} \mathrm{Tc} / \mathrm{DOX}$ according to the assigned group. SPECT imaging was carried out at $0.5,2,4,6,8$, and $12 \mathrm{~h}$ post-injection. All the rats were euthanized after SPECT imaging to separate the brains and measure their relative radioactivity intensities.

\section{Statistical analysis}

Data are presented as mean \pm standard deviation, and one-way analysis of variance was performed to evaluate the significance of the data. A p value of 0.05 was selected as the threshold of significance, and the data were denoted with $(* *)$ for $\mathrm{p}<0.01$ and $(* * *)$ for $\mathrm{p}<0.001$.

\section{Results}

\section{Characterization of the mPEI-CTX ${ }^{-99 \mathrm{~m}} T \mathrm{TC} / \mathrm{DOX}$ complex}

The theranostic complexes and the intermediate products obtained during the preparation process were characterized using different techniques. Firstly, ${ }^{1} \mathrm{H}$ nuclear magnetic resonance (NMR) spectroscopy was used to characterize the intermediate products including PEI. $\mathrm{NH}_{2}$ - $m$ PEG, PEI.NH $2_{2}$ (PEG-MAL)-mPEG, PEI.NH $2_{2}$ (PEG-CTX)-mPEG, PEI.NH ${ }_{2}$-DTPA-(PEG-MAL)- $m$ PEG, and PEI.NH ${ }_{2}$-DTPA-(PEG-CTX)- $m$ PEG. As shown in Additional file 1: Fig. S1a and S1b, the peaks at 3.5$3.7 \mathrm{ppm}$ could be assigned to the aromatic protons of PEG, while the peaks at $1.0-1.5 \mathrm{ppm}$ were attributed to the protons of CTX (Fig. 1c). By NMR integration analysis, each PEI was estimated to have 13.3 mPEG, 14.2 PEG-MAL, and 5.4 CTX moieties. Likewise, the average number of DTPA moieties (at $3.8 \mathrm{ppm}$ ) attached onto each PEI was measured to be approximately 7.5 and 7.2 , as shown in Additional file 1: Fig. S1d and S1e, respectively.

Secondly, after acetylation of the PEI.NH ${ }_{2}$-DTPA(PEG-CTX)- $m$ PEG and PEI.NH ${ }_{2}$-DTPA-(PEG-MAL)$m$ PEG, the $m$ PEG-CTX and $m$ PEG were formed, and then was used for the encapsulation of DOX to synthesize the $m$ PEI-CTX/DOX and $m \mathrm{PEI} / \mathrm{DOX}$ complexes, which could be easily dissolved in different solvents such as water and cell culture media (Additional file 1: Fig. S2a-f). Subsequently, UV-vis spectroscopy was performed to confirm the loading of DOX. As shown in Fig. 2a, the mPEI-CTX/DOX complex showed an enhanced absorption at $490 \mathrm{~nm}$, which was related to the typical absorption peak of DOX in the UV-vis spectra, while no absorption at this wavelength could be observed for the intermediate products PEI.NH H $_{2}$ (PEG-CTX)$m$ PEG and PEI.NH ${ }_{2}$-DTPA-(PEG-CTX)- $m$ PEG without DOX. The amount of DOX loaded within mPEI-CTX/ DOX complex was calculated to be 20.07 DOX molecules per PEI and the DOX percentage reached 7.02\%, which was calculated and analyzed via the standard DOX absorbance/concentration calibration curve (Additional file 1: Fig. S2g-i). Similar results were found for the $m \mathrm{PEI} /$ DOX complex. Into each PEI, 19.70 DOX molecules were encapsulated, and the DOX percentage was calculated to be $6.99 \%$. Meanwhile, the hydrodynamic size and zeta 

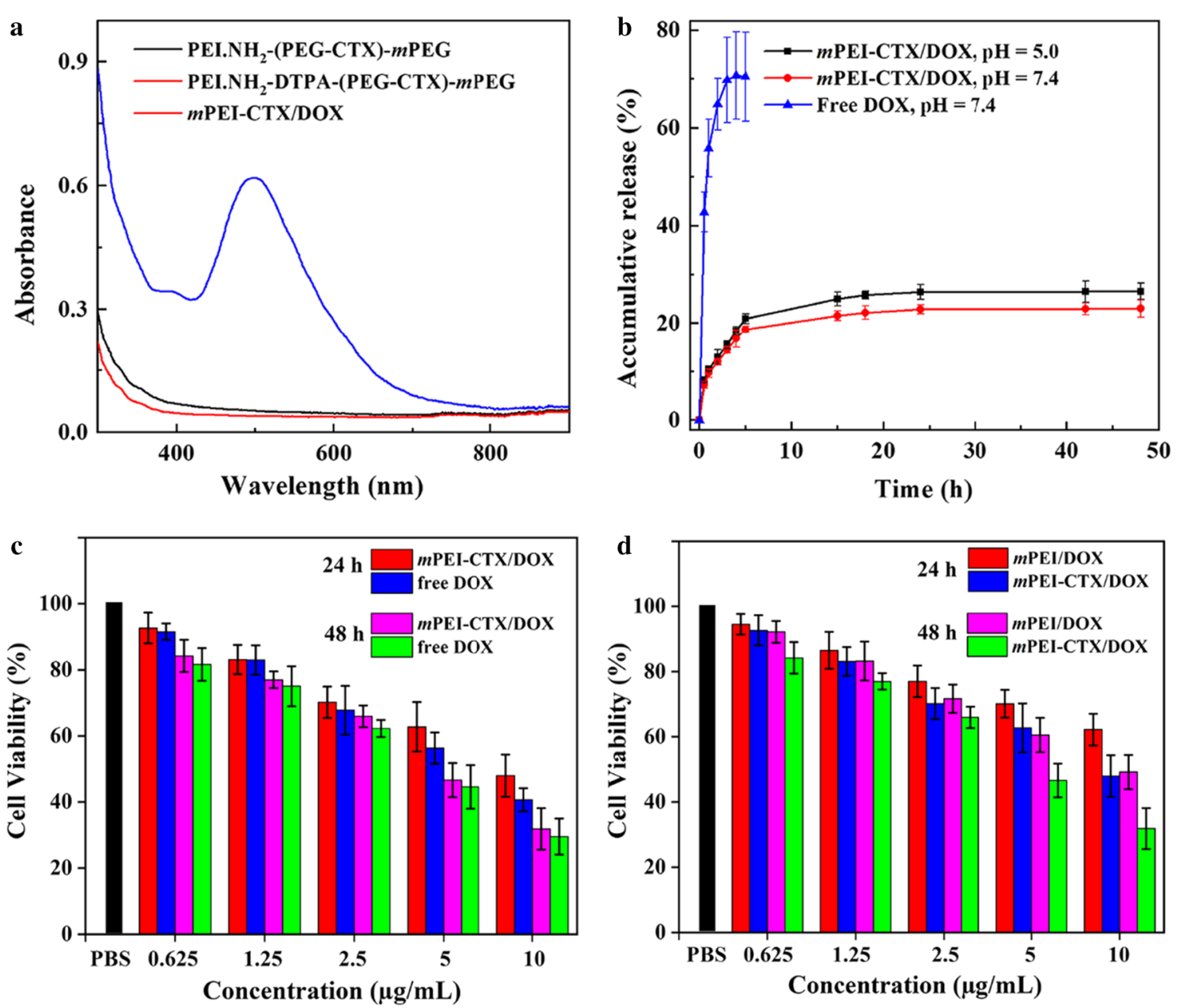

Fig. 2 a UV-Vis spectra of PEI.NH 2 -(PEG-CTX)-mPEG, PEI.NH 2 -DTPA-(PEG-CTX)- $m$ PEG, and $m$ PEI-CTX/DOX dispersed in water at a polymer concentration of $200 \mu \mathrm{g} / \mathrm{mL}$. $\mathbf{b}$ Cumulative release of DOX from $\mathrm{mPEI}-\mathrm{CTX} / \mathrm{DOX}$ in PBS buffer $(\mathrm{pH}=7.4)$ and acetate buffer $(\mathrm{pH}=5.0)$ at $37^{\circ} \mathrm{C}$. $\mathbf{c}$ and d CCK-8 assay of C6 cells treated with mPEI-CTX/DOX, mPEI/DOX, and free DOX at different DOX concentrations for 24 and $48 \mathrm{~h}$

potential value of $m$ PEI-CTX/DOX complex were measured by dynamic light scattering. As shown in Additional file 1: Table S1 and Fig. S3a-c, the hydrodynamic sizes of both $m$ PEI-CTX/DOX and $m$ PEI/DOX complexes had relatively uniform distributions and were larger than that of $m$ PEI-CTX before DOX loading, which reflected the success of DOX loading. As shown in Table S2, the zeta potentials of PEI.NH ${ }_{2}$-DTPA-(PEG-CTX)- $m$ PEG and $m$ PEI-CTX/DOX showed no significant difference under different $\mathrm{pH}$ values, suggesting that the DOX loading did not obviously change the surface potentials of the complexes. Furthermore, the surface potentials of both $m \mathrm{PEI} /$ DOX and $m$ PEI-CTX/DOX complexes under a slightly acidic environment $(\mathrm{pH}=5.0)$ were more positive than those under physiological condition $(\mathrm{pH}=7.4)$. This was likely due to the protonation of partial PEI tertiary amines under a slightly acidic environment $(\mathrm{pH}=5.0)$, as observed in previous studies [46-48].
Thirdly, the release kinetics of DOX from the $m$ PEICTX/DOX complex were analyzed under two different $\mathrm{pH}$ conditions (Fig. 2b). We found that DOX release occurred more rapidly in the initial phase than in the latter, which is in good agreement with that reported previously [45]. At $48 \mathrm{~h}$, the DOX release percentage could be achieved at $26.6 \%(\mathrm{pH}=5.0)$ and $22.9 \%$ $(\mathrm{pH}=7.4)$, respectively.

Finally, $m$ PEI-CTX/DOX was effectively radiolabeled with ${ }^{99 \mathrm{~m}} \mathrm{Tc}$ via DTPA. Instant thin-layer chromatography (ITLC) was used to assess the radiochemical yields (RCYs) and stabilities of the ${ }^{99 \mathrm{~m}} \mathrm{Tc}$-labeled PEI-based NPs. The RCYs of $m$ PEI-CTX- ${ }^{99 \mathrm{~m}} \mathrm{Tc} / \mathrm{DOX}$ and $m$ PEI- ${ }^{99 \mathrm{~m}} \mathrm{Tc} / \mathrm{DOX}$ were found to be $80.3 \pm 2.8 \%$ and $78.8 \pm 0.9 \%(n=5)$, respectively. After PD-10 column purification, the radiochemical purities of both $m$ PEI-CTX- ${ }^{99 \mathrm{~m}} \mathrm{Tc} / \mathrm{DOX}$ and $m$ PEI $-{ }^{99 \mathrm{~m}} \mathrm{Tc} / \mathrm{DOX}$ were over $99 \%$ (Additional file 1: Fig. S3d-f), and remained above $95 \%$ after $12 \mathrm{~h}$ in phosphate 
buffered saline (PBS) at room temperature (Additional file 1: Fig. S4a), indicating excellent stabilities in vitro.

\section{In vitro cytotoxicity assays}

CCK-8 assay was used to test the cytocompatibility of $m$ PEI-CTX without DOX encapsulation and evaluate the therapeutic efficacy of the $m$ PEI-CTX/DOX complex against C6 cells in vitro. As shown in Additional file 1: Fig. S4b, $m$ PEI and $m$ PEI-CTX displayed little cytotoxicity, and the viabilities of C6 cells after treatment remained more than $90 \%$ for all the studied polymer concentrations at $24 \mathrm{~h}$ and $48 \mathrm{~h}$. On the contrary, the growth of C6 cells was significantly inhibited by the mPEI-CTX/ DOX complex and free DOX in a dose-dependent and time-dependent manner (Fig. 2c). After exposure to the $m$ PEI-CTX/DOX complex and free DOX for $48 \mathrm{~h}$ at the DOX concentration of $10 \mu \mathrm{g} / \mathrm{mL}, 31.9 \%$ and $29.5 \%$ of C6 cells, respectively, survived. The half maximal inhibitory concentration $\left(\mathrm{IC}_{50}\right)$ values of $m \mathrm{PEI}-\mathrm{CTX} / \mathrm{DOX}$ and free DOX were calculated to be $9.18 \mu \mathrm{g} / \mathrm{mL}$ and $6.59 \mu \mathrm{g} / \mathrm{mL}$ at $24 \mathrm{~h}$, respectively, and their corresponding $\mathrm{IC}_{50}$ values decreased to $4.87 \mu \mathrm{g} / \mathrm{mL}$ and $4.36 \mu \mathrm{g} / \mathrm{mL}$, respectively, as the incubation time increased to $48 \mathrm{~h}$.

The targeted antitumor efficacy of the mPEI-CTX/ DOX complex was also evaluated using CCK-8 assay in vitro. Compared with the $m \mathrm{PEI} / \mathrm{DOX}$ complex without CTX modification, the targeted $m$ PEI-CTX/DOX complex displayed a stronger inhibitory effect on C6 cells proliferation (Fig. 2d). The viabilities of C6 cells incubated with the mPEI-CTX/DOX complex were much weaker than that of the cells treated with $m \mathrm{PEI} / \mathrm{DOX}$ at the same DOX concentrations and time points. The cell survival rate after the $m$ PEI-CTX/DOX complex treatment at the DOX concentration of $10 \mu \mathrm{g} / \mathrm{mL}$ for $48 \mathrm{~h}$ (31.9\%) was much smaller than that after $m \mathrm{PEI} / \mathrm{DOX}$ complex (49.2\%) treatment under the same condition.

Furthermore, we checked the cytoskeleton and nucleus of the cells after treatment (Fig. 3). Obviously, in the absence of DOX such as in the PBS and mPEI-CTX groups, the cytoskeleton and nucleus of the treated cells maintained a normal state, and no cytoskeletal injury or cellular membrane dysfunction could be observed.

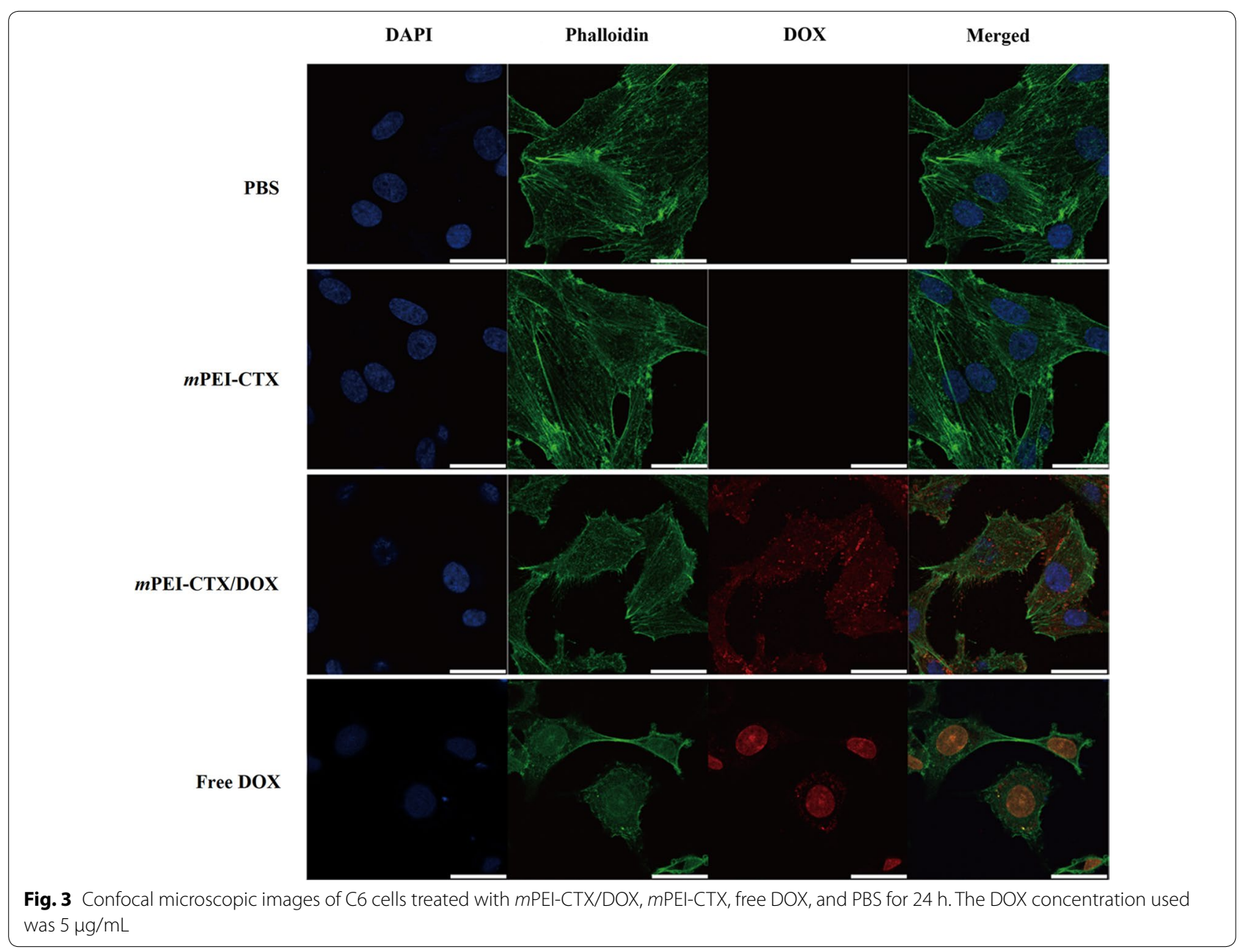


In contrast, severe cytoskeleton damage occurred in C6 cells after incubation with the $m$ PEI-CTX/DOX complex and free DOX, and the cytoskeleton of cells treated with the $m$ PEI-CTX/DOX complex was almost completely destroyed.

\section{In vitro targeting specificity}

To investigate the targeting specificity of the $m$ PEI-CTX/ DOX complex in vitro, the fluorescence intensities of DOX in C6 cells were qualitatively tested using confocal laser scanning microscopy (CLSM) and quantitatively analyzed using flow cytometry. As shown in Fig. 4, CLSM revealed that the $\mathrm{C} 6$ cells incubated with the $\mathrm{mPEI}-\mathrm{CTX} /$ DOX complex had more intense red DOX fluorescence signals both inside the cytosol and on the surface of the cells than those incubated with the $m$ PEI/DOX complex. Similarly, because of the presence of DOX, the targeting specificity of the $m$ PEI-CTX/DOX complex could be evaluated by flow cytometry. As shown in Fig. 5a and $5 \mathrm{~b}$, the C6 cells incubated with the $m$ PEI-CTX/DOX complex for $4 \mathrm{~h}$ showed significantly higher DOX fluorescence signals compared with those treated with free DOX at the same DOX concentration.

The cellular uptake of $m$ PEI-CTX/DOX by C6 cells after ${ }^{99 \mathrm{~m}} \mathrm{Tc}$ radiolabeling was also validated in vitro. After incubation with $m$ PEI-CTX- ${ }^{99 \mathrm{~m}} \mathrm{Tc} / \mathrm{DOX}$ or $m$ PEI- ${ }^{99 \mathrm{~m}} \mathrm{Tc} /$ DOX for $4 \mathrm{~h}$, SPECT images of these cells were acquired
(Fig. 5c and 5d). It could be clearly seen that the cells treated with $m$ PEI-CTX- ${ }^{99 \mathrm{~m}} \mathrm{Tc} / \mathrm{DOX}$ displayed higher signal intensities than those treated with $m \mathrm{PEI}-{ }^{99 \mathrm{~m}} \mathrm{Tc} /$ DOX at different radioactive concentrations. The SPECT signal intensity of $m$ PEI-CTX- ${ }^{99 \mathrm{~m}} \mathrm{Tc} / \mathrm{DOX}$ was much higher than that of $m \mathrm{PEI}-{ }^{99 \mathrm{~m}} \mathrm{Tc} / \mathrm{DOX}$ at the highest ${ }^{99 \mathrm{~m}} \mathrm{Tc}$ concentration.

\section{In vivo SPECT imaging and antitumor efficacy} in a subcutaneous glioma tumor model

To evaluate the performance of $m$ PEI-CTX- ${ }^{99 \mathrm{~m}} \mathrm{Tc} /$ DOX in vivo, SPECT imaging was performed using a xenografted nude mouse model. Unsurprisingly, the ${ }^{99 \mathrm{~m}}$ Tc-radiolabeled CTX-modified PEI complex exhibited acceptable SPECT imaging results (Fig. 6a and $6 \mathrm{~b})$. The tumor accumulation of $m$ PEI-CTX ${ }^{-99 \mathrm{~m}} \mathrm{Tc} /$ DOX could be observable at $2 \mathrm{~h}$ post-injection, which increased with the progression of time. Higher signal intensities could be found in tumor regions at $4 \mathrm{~h}$, and $6 \mathrm{~h}$ post-injection, and the highest seemed to be at $8 \mathrm{~h}$ post-injection followed by attenuated tumor accumulation at $12 \mathrm{~h}$ post-injection. Conversely, inconspicuous SPECT signal intensity changes could be found in the tumors for $12 \mathrm{~h}$ following the injection of $m \mathrm{PEI}-{ }^{99 \mathrm{~m}} \mathrm{Tc} /$ DOX, suggesting the key role of CTX peptide in the process of glioma-targeting. This could be further confirmed by the SPECT image of ex vivo tumors at $12 \mathrm{~h}$

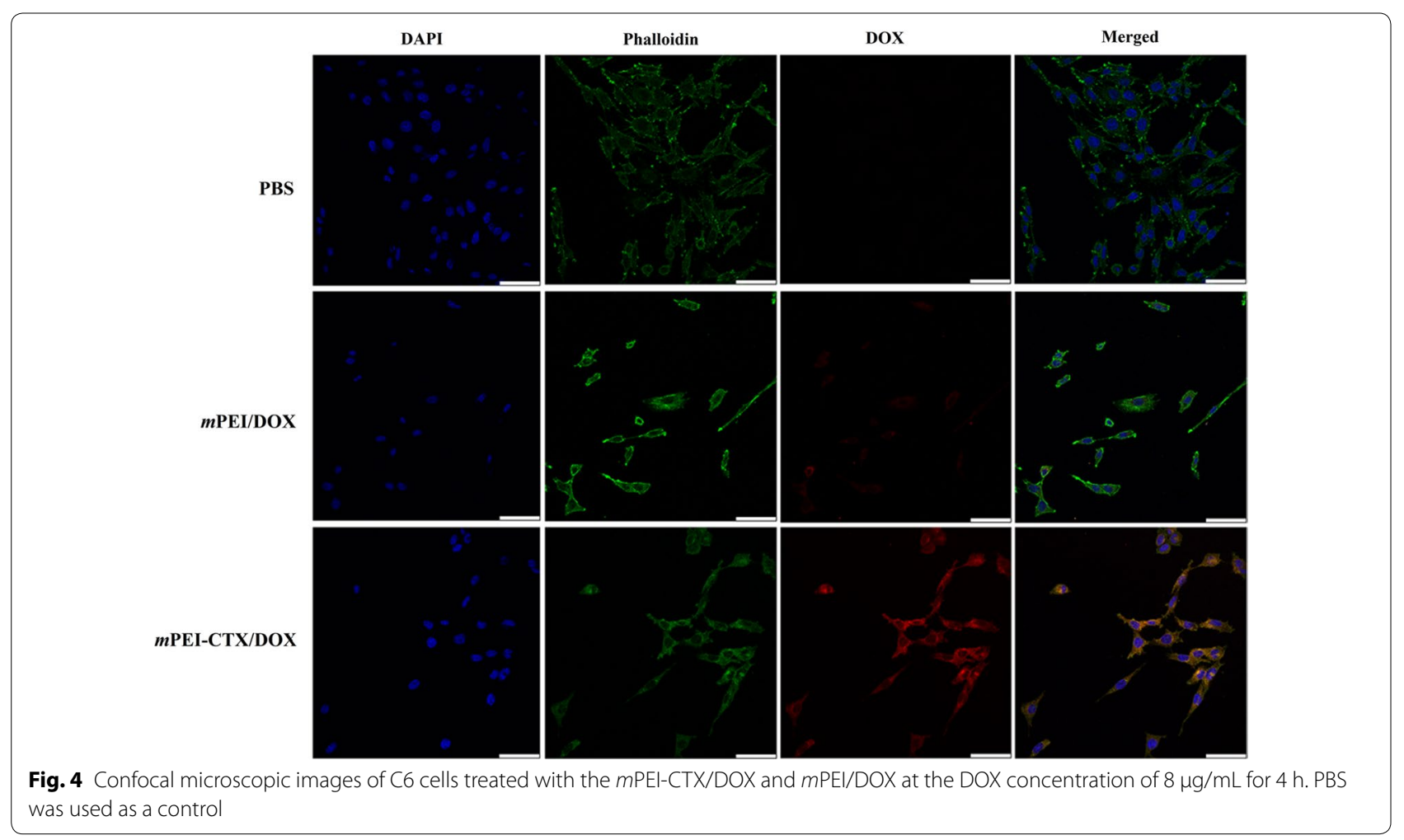




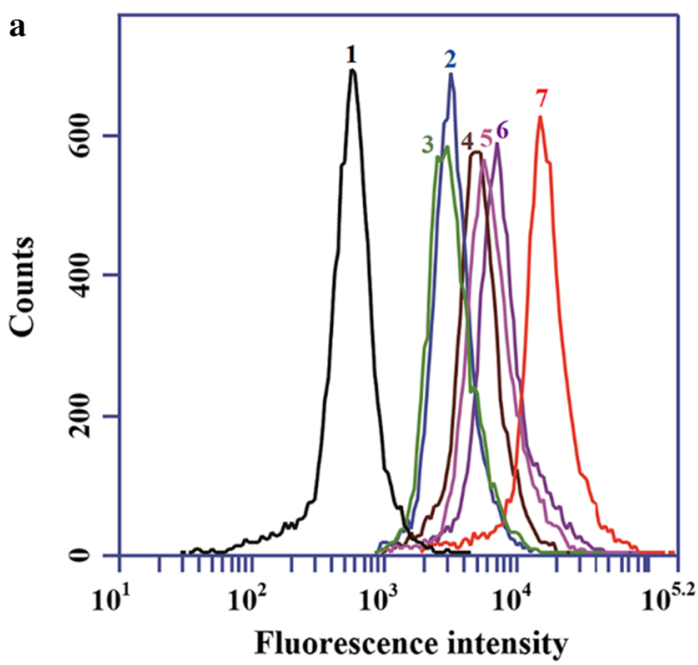

b
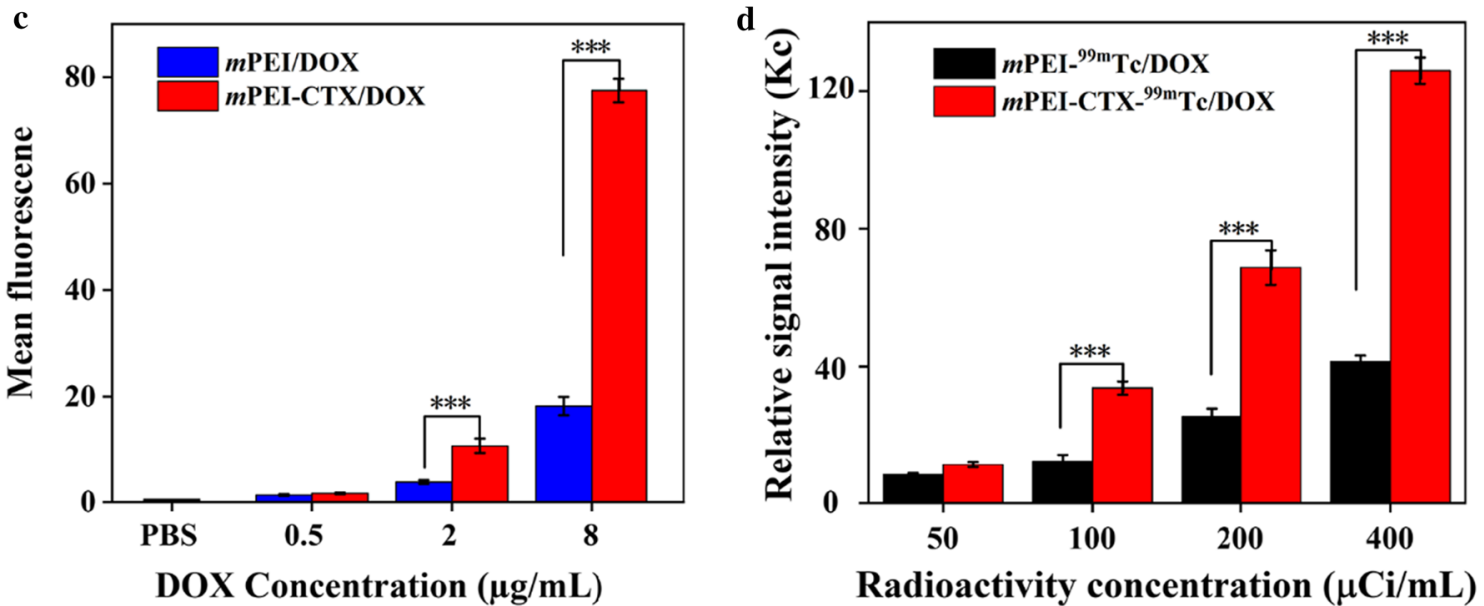

Fig. 5 a The comparison and $\mathbf{b}$ flow cytometric analysis of C6 cells treated with $m P E I-C T X / D O X$ and $m P E I / D O X$ at different DOX concentrations for $4 \mathrm{~h}$. Concentrations were (1) PBS, (2) $0.5 \mu \mathrm{g} / \mathrm{mL} \mathrm{mPEI} / \mathrm{DOX}$, (3) $0.5 \mu \mathrm{g} / \mathrm{mL} \mathrm{mPEl}-\mathrm{CTX} / \mathrm{DOX}$, (4) $2 \mu \mathrm{g} / \mathrm{mL} \mathrm{mPEI} / \mathrm{DOX}$, (5) $2 \mu \mathrm{g} / \mathrm{mL} \mathrm{mPEI}-\mathrm{CTX} / \mathrm{DOX}$, (6)

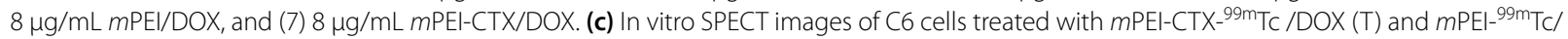
DOX (NT) for $4 \mathrm{~h}$ at the radioactivity concentrations of 50,100, 200, and $400 \mu \mathrm{Ci} / \mathrm{mL}$, and $\mathbf{d}$ their relative SPECT signal intensities

post-injection (Fig. 6c), and much higher tumor SPECT signal intensity was observed in the mice treated with $m$ PEI-CTX- ${ }^{99 m} \mathrm{Tc} / \mathrm{DOX}$. In addition, biodistribution studies were performed at $12 \mathrm{~h}$ post-injection to analyze the accumulation of $m$ PEI-CTX $-{ }^{99 m} \mathrm{Tc} / \mathrm{DOX}$ and $m$ PEI- ${ }^{99 m} \mathrm{Tc} / \mathrm{DOX}$ in major organs (Fig. S5). Similar to the high radioactive intensities in SPECT images of the abdomen of mice, the biodistribution data showed that both the $m$ PEI-CTX- ${ }^{99 \mathrm{~m}} \mathrm{Tc} / \mathrm{DOX}$ and $m$ PEI- ${ }^{99 \mathrm{~m}} \mathrm{Tc} / \mathrm{DOX}$ were mainly accumulated in the liver, kidneys, and spleen with mild accumulation in the lung, heart, and intestines, which resulted in low radioactivity uptake in other orangs such as the stomach and muscle. Notably, the mice treated with $m$ PEI-CTX- ${ }^{99 \mathrm{~m}} \mathrm{Tc} / \mathrm{DOX}$ exhibited a higher tumor uptake than those treated with $m$ PEI${ }^{99 \mathrm{~m}} \mathrm{Tc} / \mathrm{DOX}$ (4.72 $\pm 0.19 \mathrm{ID} \% / \mathrm{g}$ vs $\left.1.61 \pm 0.18 \mathrm{ID} \% / \mathrm{g}\right)$, further corroborating the targeting specificity of $m$ PEICTX- ${ }^{99 m} \mathrm{Tc} / \mathrm{DOX}$ in vivo.

Subsequently, the in vivo antitumor effect of the $m$ PEI-CTX/DOX complex was investigated using the xenografted tumor model. The $m$ PEI/DOX, $m$ PEI-CTX, $m$ PEI, free DOX, and saline were used as the control groups. The ability to inhibit tumor growth was in the followed the order: $m$ PEI-CTX/DOX $>$ free $\mathrm{DOX}>m \mathrm{PEI} /$ $\mathrm{DOX}>m \mathrm{PEI}-\mathrm{CTX} \approx m \mathrm{PEI} \approx$ saline (Fig. 7a). Inhibition of tumor growth in the $m$ PEI-CTX/DOX complex group was higher than that in the control groups, and the relative tumor volumes after the 21-day treatment in each group had increased $5.77 \pm 0.68$ ( $m$ PEI-CTX/ DOX), $9.26 \pm 1.51$ (free DOX), $15.1 \pm 1.67$ ( $m$ PEI/DOX), $21.8 \pm 2.58$ (mPEI-CTX), $23.42 \pm 2.09$ (mPEI), and $25.47 \pm 2.19$ (saline) times, respectively. The antitumor 


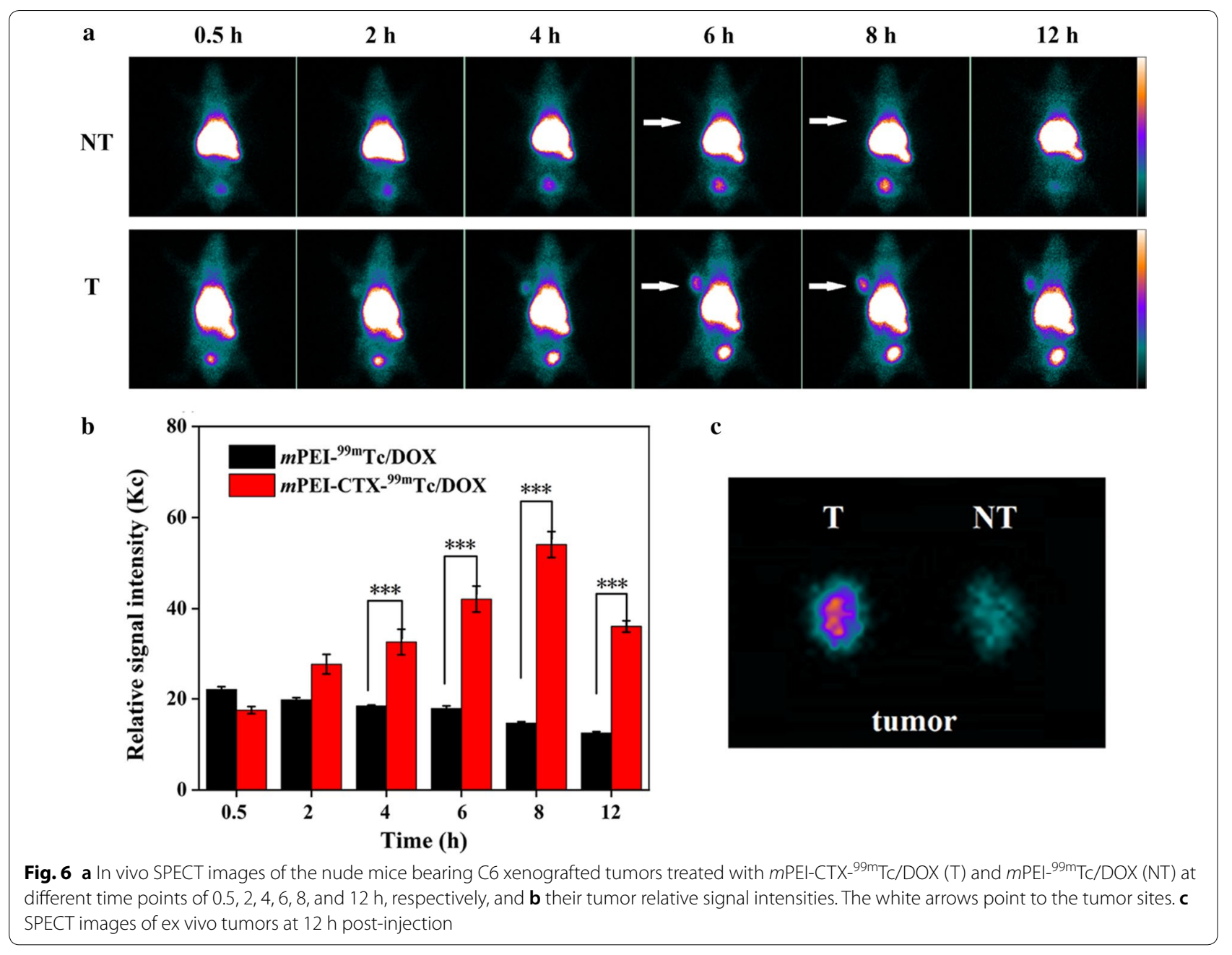

effect of the designed $m$ PEI-CTX/DOX complex could also be confirmed by the survival rate data (Fig. 7b). In the studied time period, the survival rate followed the same order of the ability to inhibit tumor growth, and the mice in the $m$ PEI-CTX/DOX complex group displayed the longest survival time. The overall survival time was 51 days in the $m$ PEI-CTX/DOX complex group and 40 days in the $m \mathrm{PEI} / \mathrm{DOX}$ complex group, which was longer than that in the other control groups. This further demonstrated that the CTX modification enhanced the anti-glioma effect and prolonged survival time by specific targeting. Furthermore, the toxicity and side effects of the drug delivery systems were evaluated according to body weights of the mice during the entire treatment period. As shown in Additional file 1: Fig. S6, a slighter body weight loss was observed in the mice of the free DOX group than those of the other groups, indicating certain toxicity of free DOX to the mice. However, the mice of the $m$ PEI-CTX/DOX complex group and those of the other control groups showed no significant differences in weights. This seems to be explained by the inhibited toxicity of DOX after being encapsulated into the PEGylated PEI.

Subsequently, we performed HE and TUNEL staining to check the biosafety and therapeutic effect of the developed $m$ PEI-CTX/DOX complex. As shown in Fig. 7c, the H\&E staining showed that the tumor sections exhibited well-shaped cells. No obvious necrotic areas could be observed in the $m$ PEI-CTX, $m$ PEI, and saline groups, while the tumor necrosis was apparent in the other groups. The $m$ PEI-CTX/DOX group showed a much larger necrotic area than the $m$ PEI/DOX and free DOX groups, indicating that the CTX-modified complex had the strongest anticancer efficiency among the studied groups. Similarly, as shown in Fig. 7d, TUNEL assay revealed no apoptotic cells in the saline, $m$ PEI, and $m$ PEI-CTX groups. Unlike the $m$ PEI/DOX and free DOX groups, which showed a small number of apoptotic cells, the $m$ PEI-CTX/DOX group displayed obvious positive staining of apoptotic cells, confirming 

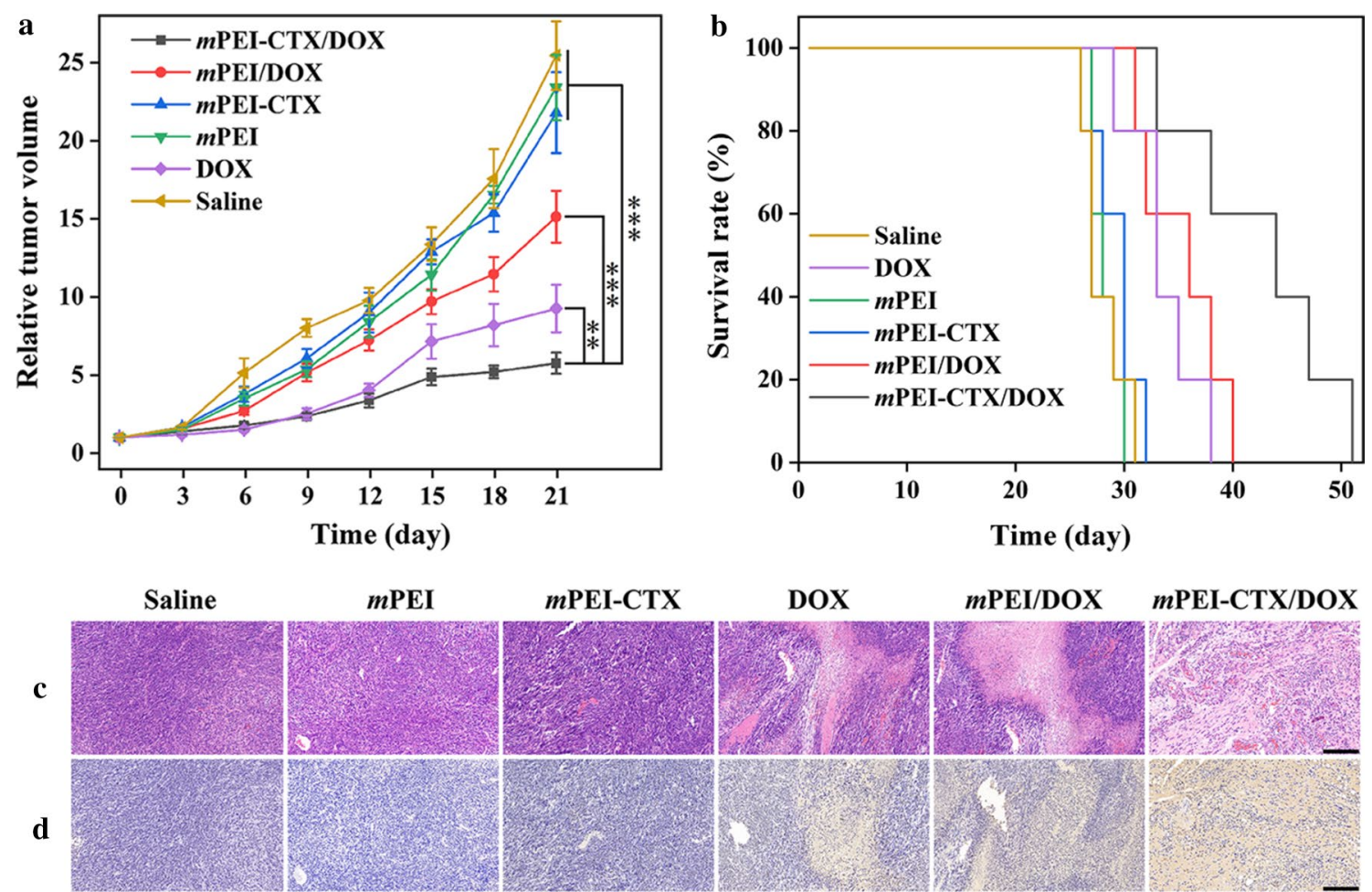

Fig. 7 a Relative tumor volume of C6 xenografted tumors in nude mice treated with mPEI-CTX/DOX, mPEI/DOX, $m$ PEI-CTX, $m P E I, D O X$, and saline, respectively. The relative tumor volume was normalized according to their initial tumor volume (mean $\pm S D, n=6)$. b Survival rate, $\mathbf{c} H \& E$ staining and $\mathbf{d}$ TUNEL assay results of $\mathrm{C} 6$ tumor-bearing mice after various treatments (mean $\pm S D, n=6$ ). The scale bar shown in both panels represents $200 \mu \mathrm{m}$

the antitumor performance in vivo. In addition, the biosafety in the complex in vivo system was checked by observing the H\&E stained morphology of the major organs of tumor-bearing mice after treatment (Additional file 1: Fig. S7). Myocardial damage could be found in the free DOX group because of the compound's cardiotoxicity; however, no obvious damages to the hearts were observed after the encapsulation of DOX into the carriers. As for other major organs, no obvious tissue damage, necrotic areas, or abnormalities could be found in the six groups after treatment. These results revealed the good organ compatibility and low systemic toxicity of the synthesized mPEI-CTX/DOX complex to the mice.

\section{Targeted SPECT imaging of glioma in an orthotopic rat glioma model}

In view of the unique biological properties of CTX, we evaluated the $\mathrm{BBB}$ penetrability and targeting ability of the $m$ PEI-CTX/DOX complex using Sprague Dawley (SD) rats bearing intracranial glioma in vivo. The $m$ PEICTX/DOX and $m$ PEI/DOX complexes after ${ }^{99 \mathrm{~m}} \mathrm{Tc}$ radiolabeling were injected via tail vein, and their SPECT images were acquired at different time points. As shown in Fig. 8a, the $m$ PEI-CTX- ${ }^{99} \mathrm{~m}$ Tc/DOX crossed the BBB, and the tumor uptake in the brains was observable after its accumulation for $2 \mathrm{~h}$, followed by increased signal intensities at tumor sites at $4 \mathrm{~h}$ post-injection. The tumor SPECT signal intensities seemed to be stronger at 6 and $8 \mathrm{~h}$ post-injection, and they could still be detectable at $12 \mathrm{~h}$ post-injection. On the contrary, during the studied period, the rats injected with the $m \mathrm{PEI}-{ }^{99 \mathrm{~m}} \mathrm{Tc} / \mathrm{DOX}$ complex without CTX modification exhibited insignificant radioactivity accumulation in the glioma regions. These data indicated that CTX peptide could promote the BBB penetrability and glioma-targeting efficiency in PEI-based drug delivery systems. Furthermore, unlike the stable tumor-to-background ratio (TBR) in the rats treated with $m$ PEI- ${ }^{99 \mathrm{~m}} \mathrm{Tc} / \mathrm{DOX}$ (Fig. $8 \mathrm{~b}$ ), a rising trend of TBR values was observed in the rats injected with $m$ PEI-CTX- ${ }^{-99 m} \mathrm{Tc} /$ DOX, which revealed the efficient BBB penetrability and targeting effect. This could also be confirmed by the obvious difference of the signal intensities in the brains resected from the rats after SPECT imaging (Fig. 8c). 


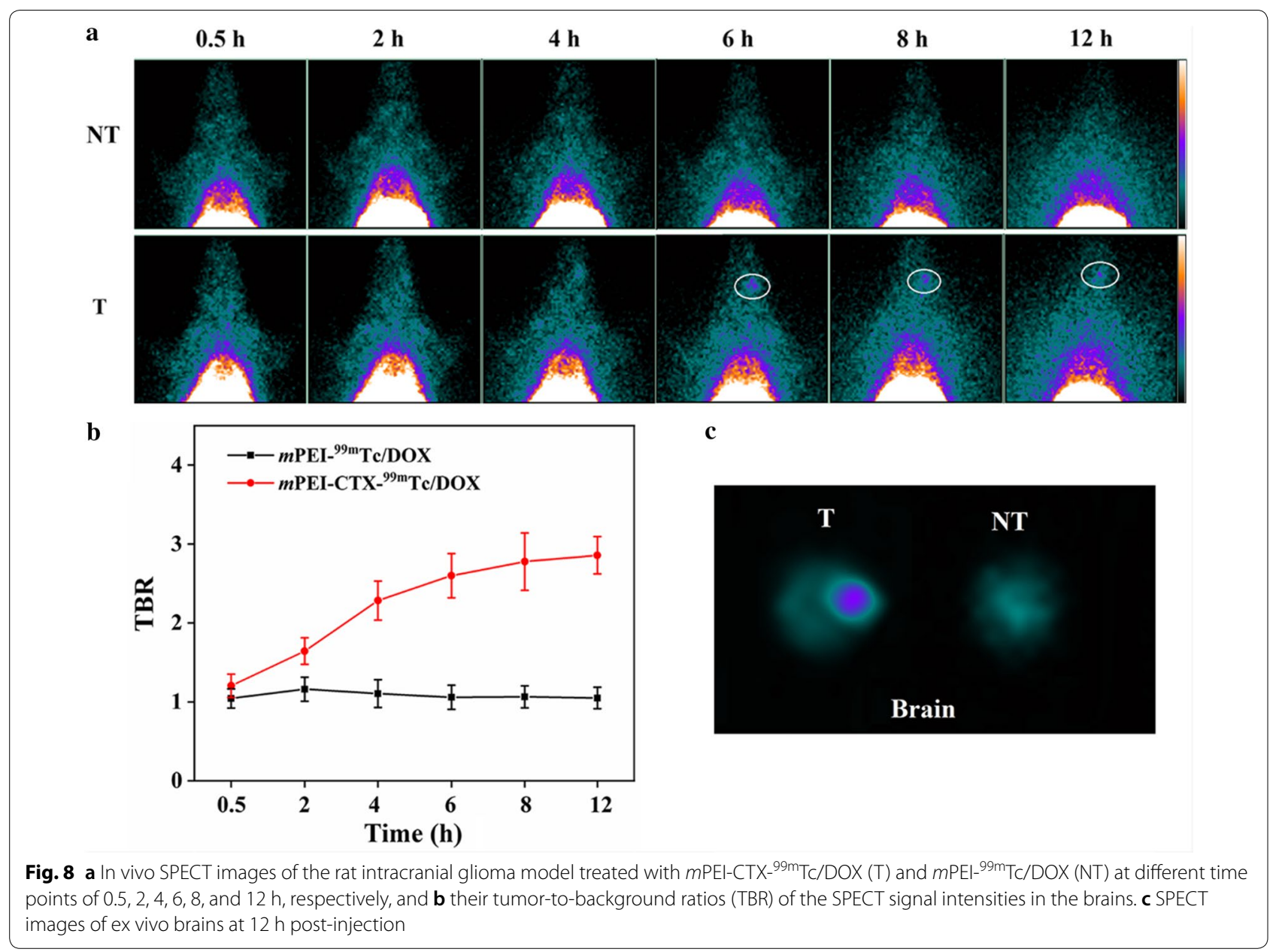

\section{Discussion}

Malignant glioma remains the deadliest brain tumor in adults. Among the currently available methods including surgery, radiotherapy and chemotherapy, surgical excision is considered as the primary method; however, it is impossible to remove tumor tissue entirely, leading to an extreme high risk of postoperative recurrence. Radiotherapy can prolong the survival time, but its therapeutic effect is limited to glioma cells that are radiation sensitive. Chemotherapy plays an extremely important role in the comprehensive treatment of gliomas to achieve significant therapeutic effects and good prognosis. Unfortunately, the physiological functions of the BBB allow very few chemotherapy options for gliomas at an early stage, and their obvious toxic and side effects can be brutal, leading to difficult decisions for clinicians and patients. Therefore, investigation of effective methods to promote chemotherapy drugs across $\mathrm{BBB}$ has become a focus point in the field of glioma treatment.

With the development of nanomedicine, branched PEI has become a powerful nanocarrier to construct drug delivery systems for various tumors due to its biocompatibility and tunable properties. The PEI surface amines are easily modified with PEG for PEGylation, which has been used as an effective strategy to overcome the systemic clearance and improve the pharmacokinetic properties $[45,47]$. In our previous studies, PEGylated PEI was developed as multifunctional templates to entrap gold NPs, label radionuclides, or load drugs for tumor imaging and treatment [48-50]. These PEI-based NPs could also be modified with targeting ligands for different tumors, for example, folic acid for cervical carcinoma and arginine-glycine-aspartic acid peptide for hepatic carcinoma $[45,50]$. Moreover, we developed PEI-based NPs for glioma radionuclide imaging and therapy. Due to the modification of CTX, the formed nanosystem possessed the ability to cross the BBB and target glioma cells [42]. In this study, CTX-modified PEI was further explored to build a BBB-penetrating nanocarrier for anticancer drug delivery of DOX, and the tumor accumulation of the prepared nanocarrier could be real-time monitored through SPECT imaging after ${ }^{99 \mathrm{~m}} \mathrm{Tc}$ radiolabeling. Following a 
similar synthesis method, PEI was consecutively connected with $m$ PEG, CTX, and DTPA. After acetylation of the remaining PEI surface amines using $\mathrm{AcO}_{2}, m$ PEICTX was loaded with DOX to synthesize the $m$ PEICTX/DOX complex that could be further conveniently radiolabeled with ${ }^{99 \mathrm{~m}} \mathrm{Tc}$ for SPECT imaging.

Prior to in vitro biological evaluation, the solubilities and DOX release kinetics of synthesized mPEI-CTX/ DOX complex were well tested. The data indicated that this complex had excellent dispersibility in different solvents (water, cell culture medium, and methanol), and could sustainably release DOX with a faster rate under the $\mathrm{pH}$ value of 5.4. The faster DOX release rate under the acidic condition was likely due to high water solubility of most protonated DOX molecules, which leads to the repulsion of the protonated positively charged PEI backbone and enhanced DOX release from the $m$ PEICTX/DOX complex. With respect to the anticancer effect on glioma cells, as we expected, $m$ PEI-CTX/DOX was found to observably kill glioma cells in a dose- and time-dependent manner, while $m$ PEI-CTX without DOX was non-cytotoxic to glioma cells in the given concentration range in the same time period. Clearly, the therapeutic efficacy of PEI-based NPs was only relevant to the antitumor drug DOX. The $m$ PEI-CTX/DOX complex showed a higher $\mathrm{IC}_{50}$ value than free DOX, which might be ascribed to the gradual release of antitumor drug from the $m \mathrm{PEI}-\mathrm{CTX} / \mathrm{DOX}$ complex, that is, the concentration of the released DOX form the complex was lower than that of free DOX at a given time point. Besides, the severe cytoskeleton damage was observed by confocal microscopy in the glioma cells treated with the $m$ PEICTX/DOX complex and free DOX, further confirming the equivalent therapeutic effect between them in vitro. It was worth noting that the $m$ PEI-CTX/DOX complex displayed a stronger inhibitory effect than $m$ PEI/DOX on C6 cells proliferation. This result suggested that the targeting ability of CTX made the $m$ PEI-CTX/DOX complex suitable for specific cellular uptake, thus enhancing cytotoxicity. The targeting ability of $m$ PEI-CTX/DOX was also observed using CLSM and flow cytometry in vitro. Due to the targeting ability of CTX and internalization of the complex into the cytoplasm of C6 cells, the $m \mathrm{PEI}-\mathrm{CTX} / \mathrm{DOX}$ had stronger DOX fluorescence intensity than $m \mathrm{PEI} / \mathrm{DOX}$ at the same DOX concentration. In addition, compared to $m$ PEI $-{ }^{99 \mathrm{~m}} \mathrm{Tc} / \mathrm{DOX}$, higher cellular uptake of $m$ PEI-CTX- ${ }^{99 m} \mathrm{Tc} / \mathrm{DOX}$ by C6 cells suggested that the targeting ability of $m \mathrm{PEI}-\mathrm{CTX} / \mathrm{DOX}$ was unaffected by ${ }^{99 \mathrm{~m}} \mathrm{Tc}$ radiolabeling. The imaging performance of $m$ PEI-CTX- ${ }^{99 \mathrm{~m}} \mathrm{Tc} / \mathrm{DOX}$ in vitro further supported the flow cytometry and CLSM data, which led to the assessment of the applicability of the synthesized complex for targeted SPECT imaging and chemotherapy of glioma models of mice.

SPECT imaging was further used to confirm the tumor accumulation of $m$ PEI-CTX/DOX in vivo. In this study, ${ }^{99 \mathrm{~m}} \mathrm{Tc}$ was selected for SPECT imaging because of its latent chemical properties for radiolabeling and appropriate half-life $(6.02 \mathrm{~h})$, which is fit with the pharmacokinetic characteristics of the formed complex. In agreement with the findings of our group and other researchers, CTX-modified NPs could selectively bind to glioma cells in the subcutaneous tumor mouse model, and be able to cross the BBB and accumulate at the tumor site in the orthotopic glioma model [32-34, 41, 42]. The tumor accumulation of $m$ PEI-CTX ${ }^{-99 m} \mathrm{Tc} / \mathrm{DOX}$ could be detected at $2 \mathrm{~h}$ post-injection, increase as time prolonged and reach a peak at $8 \mathrm{~h}$ post-injection. Even $12 \mathrm{~h}$ after injection, the tumor accumulation was not significantly attenuated, which might be attributed to the synergistic effect between PEGylation and targeting ability of CTX. The PEGylation modification prolonged the blood circulation time of the complex, and CTX endowed the complex with target specificity toward glioma cells in vivo, leading to an improved cellular uptake and retention time in tumor region. The good accumulation and longterm retention of chemotherapeutic drug in tumor were indispensable for targeting therapy, as it can maximize the therapeutic effect with minimized toxicity and side effects. Owing to the advantage of PEI-based drug delivery system and the existence of CTX, $m$ PEI-CTX/DOX not only could obviously inhibit the subcutaneous tumor growth and prolong the lifetime of the tumor-bearing mice, but also did not cause any significant damage to vital organs such as the heart, liver and kidneys, when compared to the direct treatment with DOX alone. These results highlighted the potential of formed $m$ PEI-CTX/ DOX complex as an anticancer drug delivery system for glioma treatment; however, additional studies should be conducted to investigate the therapeutic effect of this complex on intracranial gliomas and its value in therapeutic monitoring in future studies.

\section{Conclusions}

In this study, we designed and synthesized a PEI-based drug delivery system for targeted glioma therapy. The dendritic PEI could be readily modified with CTX peptide on the surface, and effectively encapsulate the anticancer drug DOX into the interior cavities. This CTX-functionalized PEI-based drug delivery system could release DOX in a $\mathrm{pH}$-sensitive manner and displayed good targeting ability and therapeutic efficacy toward glioma cells in vitro and in vivo (a subcutaneous tumor model). More importantly, owing to the unique biological characters of CTX, the developed drug delivery 
system was able to cross BBB and accumulate in the brain tumor region, and the tumor accumulation could be visualized after ${ }^{99 \mathrm{~m}} \mathrm{Tc}$ radiolabeling. This PEI-based drug carrier not only exhibited a potential strategy to overcome the challenges posed by the BBB barrier through peptide modification, but also provided a promising approach to fabricate imaging-guided drug delivery systems for different types of cancers.

\section{Supplementary information}

Supplementary information accompanies this paper at https://doi. org/10.1186/s12951-020-00705-3.

Additional file 1: Table S1. Hydrodynamic sizes of PEI.NH 2 -DTPA-(PEGCTX)- $m$ PEG, $m$ PEI-CTX/DOX and $m P E I / D O X$ complexes dispersed in water. Table S2. Zeta potential values of PEI.NH $H_{2}$-DTPA-(PEG-CTX)-mPEG, $\mathrm{mPEI}-\mathrm{CTX} / \mathrm{DOX}$ and $\mathrm{mPEI} / \mathrm{DOX}$ under different $\mathrm{pH}$ conditions. Fig. S1. ${ }^{1} \mathrm{H}$ NMR spectra of a PEI.NH $\mathrm{H}_{2}-\mathrm{mPEG}$, $\mathbf{b}$ PEI.NH $\mathrm{H}_{2}$ (PEG-MAL)-mPEG, $\mathbf{c}$ PEI. $\mathrm{NH}_{2}$-(PEG-CTX)-mPEG, d PEI.NH 2 -DTPA-(PEG-MAL)-mPEG and e PEI. $\mathrm{NH}_{2}$-DTPA-(PEG-CTX)-mPEG, respectively. $\mathbf{f}$ Schematic illustration of the mPEI-CTX structure. Fig. S2. Photographs of the MPEI-CTX/DOX (a and $\mathbf{b}$ ) and $\mathrm{mPEI} / \mathrm{DOX}$ (d and e) dispersed in water ( $\mathbf{a}$ and $\mathbf{d}$ ), cell culture medium (b and $\mathbf{e}$ ), respectively, and blank cell culture medium (c and $\mathbf{f}$ ). Standard curve of DOX dissolved in methanol (g) and PBS with pH 5.0 (h) and 7.4 (i). Fig. S3. Hydrodynamic size distributions of a PEI.NH ${ }_{2}$-DTPA-(PEG-CTX)$m P E G, \mathbf{b} m P E I / D O X$ and $\mathbf{c} m P E I-C T X / D O X$ dispersed in water. ITLC results of $\mathbf{d ~} \mathrm{Na}^{99 \mathrm{~m}} \mathrm{TcO}_{4}$ e $m$ PEI- ${ }^{-99 \mathrm{~m} T c / D O X}$ and $\mathbf{f} m \mathrm{mEI}-\mathrm{CTX} X{ }^{99 \mathrm{~m}} \mathrm{Tc} / \mathrm{DOX}$ on silica gel-coated fiber glass sheets using saline as the mobile phase. Fig. S4. a Radiochemical purities of $\mathrm{mPEI}-\mathrm{CTX}{ }^{-99 \mathrm{~m} T c / D O X}$ and $\mathrm{mPEI}-{ }^{99 \mathrm{~m}} \mathrm{Tc} / \mathrm{DOX}$ in PBS at room temperature and FBS at $37^{\circ} \mathrm{C}$ for $1,2,6$ and $12 \mathrm{~h}$. b CCK-8 assay of $\mathrm{C} 6$ cells treated with the $\mathrm{MPE}$ (or $\mathrm{mPEI}-\mathrm{CTX}$ at different polymer concentrations for 24 and $48 \mathrm{~h}$, respectively. Fig. S5. Biodistribution of the $\mathrm{mPEI}-\mathrm{CTX}-{ }^{99 \mathrm{~m}} \mathrm{Tc} / \mathrm{DOX}$ and $\mathrm{mPEI}-{ }^{-99 \mathrm{~m} T} \mathrm{~T} / \mathrm{DOX}$ at $12 \mathrm{~h}$ post-injection. Fig. S6. Body weight changes of the $\mathrm{C} 6$ tumor-bearing mice during the treatments with $m P E I-C T X / D O X, m P E I / D O X, m P E I-C T X, m P E I$, DOX and saline, respectively. The relative body weight was normalized according to their initial weights (Mean $\pm S D, n=6$ ). Fig. S7. H\&E staining of the heart, liver, spleen, lung and kidney of the tumor-bearing mice after the 21-day treatment with $m$ PEI-CTX/DOX, mPEI/DOX, mPEI-CTX, mPEI, DOX and saline. The scale bar in each panel indicates $200 \mu \mathrm{m}$.

\section{Abbreviations}

ANOVA: Analysis of variance; BBB: Blood-brain-barrier; CLSM: Confocal laser scanning microscopy; CTX: Chlorotoxin; DMEM: Dulbecco's Modified Eagle medium; DMSO: Dimethyl sulfoxide; DTPA: Diethylenetriaminepentaacetic acid; Fl: Fluorescein isothiocyanate; H\&E: Hematoxylin and eosin; ITLC: Instant thin-layer chromatography; mPEG: Methoxypolyethylene glycol; NMR: Nuclear magnetic resonance;"; NP: Nanoparticle; PBS: Phosphate buffered saline; PEG: Polyethylene glycol; PEI: Polyethyleneimine; RCY: Radiochemical yield; SPECT: Single-photon emission computerized tomography; TBR: Tumor-to-background ratio; TUNEL: Transferase dUTP nick end labeling.

\section{Acknowledgements}

Not applicable.

\section{Authors' contributions}

$M Z$, JY and JZ organized the study. LZ, JZ and JG designed and performed the experiments. NS, SW and WQ analyzed the data. LZ and JZ wrote the manuscript. JZ revised the manuscript. MZ, JY and JZ discussed the results. All authors read and approved the final manuscript.

\section{Funding}

The present study was financially supported by the National Natural Science Foundation of China (81801727, 81671712 and 21807059) and the Ningxia Key Research and Development Program (2019BEG03018). J. Zhu thanks the support from the Natural Science Foundation of Jiangsu Province (BK20180711) and the Natural Science Foundation for Colleges and Universities in Jiangsu Province (17KJB350005).

\section{Availability of data and materials}

All data generated or analyzed during this study are included in this published article.

\section{Ethics approval and consent to participate}

Animal experiments were performed using the protocol approved by the ethical committee of Shanghai General Hospital.

\section{Consent for publication}

All authors agree to be published.

\section{Competing interests}

The authors declare that they have no competing interests.

\section{Author details}

${ }^{1}$ Department of Nuclear Medicine, Shanghai General Hospital, Shanghai Jiao Tong University School of Medicine, Shanghai 200080, People's Republic of China. ${ }^{2}$ School of Pharmaceutical Sciences, Nanjing Tech University, Nanjing 211816, People's Republic of China. ${ }^{3}$ Department of Nuclear Medicine, General Hospital of Ningxia Medical University, Yinchuan 750004, Ningxia, People's Republic of China. ${ }^{4}$ School of Basic Medical Sciences, Ningxia Medical University, Yinchuan 750004, Ningxia, People's Republic of China.

Received: 14 July 2020 Accepted: 7 October 2020

Published online: 14 October 2020

\section{References}

1. Bush NAO, Chang SM, Berger MS. Current and future strategies for treatment of glioma. Neurosurg Rev. 2017:40(1):1-14.

2. Alifieris C, Trafalis DT. Glioblastoma multiforme: Pathogenesis and treatment. Pharmacol Ther. 2015;152:63-82.

3. Zhang F, Xu C, Liu C, Drug delivery strategies to enhance the permeability of the blood-brain barrier for treatment of glioma, Drug Des Devel Ther, 2015, pp. 2089-100.

4. Zhou Y, Peng Z, Seven ES, Leblanc RM. Crossing the blood-brain barrier with nanoparticles. J Control Release. 2018;270:290-303.

5. Banks WA. From blood-brain barrier to blood-brain interface: new opportunities for CNS drug delivery. Nat Rev Drug Discov. 2016;15(4):275-92.

6. Li J, Zhao J, Tan T, Liu M, Zeng Z, Zeng Y, et al. Nanoparticle Drug Delivery System for Glioma and Its Efficacy Improvement Strategies: A Comprehensive Review. Int J Nanomedicine. 2020;15:2563-82.

7. Chen M, Huang Y, Zhu X, Hu X, Chen T. Efficient Overcoming of BloodBrain Barrier by Functionalized Selenium Nanoparticles to Treat Glioma. Adv Therap. 2018;1:1800074.

8. Guan J, Zhang Z, Hu X, Yang Y, Chai Z, Liu X, et al. Cholera Toxin Subunit B Enabled Multifunctional Glioma-Targeted Drug Delivery. Adv Healthc Mater. 2017;6(23):1700709.

9. Fang J, Chiu T, Huang W, Lai Y, Hu S, Chen Y, et al. Dual-Targeting Lactoferrin-Conjugated Polymerized Magnetic Polydiacetylene-Assembled Nanocarriers with Self-Responsive Fluorescence/Magnetic Resonance Imaging for In Vivo Brain Tumor Therapy. Adv Healthc Mater. 2016;5(6):688-95.

10. Nair LV, Nair RV, Shenoy SJ, Thekkuveettil A, Jayasree RS. Blood brain barrier permeable gold nanocluster for targeted brain imaging and therapy: an in vitro and in vivo study. J Mater Chem B. 2017;5(42):8314-21.

11. Wang X, Liu G, Chen N, Wu J, Zhang J, Qian Y, et al. Angiopep2Conjugated Star-Shaped Polyprodrug Amphiphiles for Simultaneous Glioma-Targeting Therapy and MR Imaging. ACS Appl Mater Interfaces. 2020;12(10):12143-54.

12. Liu L, Xu K, Wang H, Jeremy Tan PK, Fan W, Venkatraman SS, et al. Selfassembled cationic peptide nanoparticles as an efficient antimicrobial agent. Nat Nanotechnol. 2009;4(7):457-63.

13. Rotman M, Welling MM, Bunschoten A, de Backer ME, Rip J, Nabuurs RJA, et al. Enhanced glutathione PEGylated liposomal brain delivery of 
an anti-amyloid single domain antibody fragment in a mouse model for Alzheimer's disease. J Control Release. 2015;203:40-50.

14. Liu C, Zhao Z, Gao H, Rostami I, You Q, Jia X, et al. Enhanced bloodbrain-barrier penetrability and tumor-targeting efficiency by peptidefunctionalized poly(amidoamine) dendrimer for the therapy of gliomas. Nanotheranostics. 2019;3(4):311-30.

15. Dong X. Current Strategies for Brain Drug Delivery. Theranostics. 2018;8(6):1481-93.

16. Furtado D, Björnmalm M, Ayton S, Bush Al, Kempe K, Caruso F. Overcoming the Blood-Brain Barrier: The Role of Nanomaterials in Treating Neurological Diseases. Adv Mater. 2018;30(46):1801362.

17. Han S, Zheng H, Lu Y, Sun Y, Huang A, Fei W, et al. A novel synergetic targeting strategy for glioma therapy employing borneol combination with angiopep-2-modified. DOX-loaded PAMAM dendrimer J Drug Target. 2018;26(1):86-94.

18. Agarwal S, Mohamed MS, Mizuki T, Maekawa T, Sakthi KD. Chlorotoxin modified morusin-PLGA nanoparticles for targeted glioblastoma therapy. J Mater Chem B. 2019;7(39):5896-919.

19. Gao S, Li J, Jiang C, Hong B, Hao B. Plasmid pORF-hTRAlL targeting to glioma using transferrin-modified polyamidoamine dendrimer. Drug Des Devel Ther. 2015;10:1-11.

20. Ulbrich K, Knobloch T, Kreuter J. Targeting the insulin receptor: nanoparticles for drug delivery across the blood-brain barrier (BBB). J Drug Target. 2011;19(2):125-32.

21. Zhao Y, Li D, Zhao J, Song J, Zhao Y. The role of the low-density lipoprotein receptor-related protein 1 (LRP-1) in regulating bloodbrain barrier integrity \%J Reviews in the Neurosciences. Rev Neurosci. 2016;27(6):623-34.

22. Bavo F, Pucci S, Fasoli F, Lammi C, Moretti M, Mucchietto V, et al. Potent Antiglioblastoma Agents by Hybridizing the Onium-Alkyloxy-Stilbene Based Structures of an a7-nAChR, a9-nAChR Antagonist and of a ProOxidant Mitocan. J Med Chem. 2018;61 (23):10531-44.

23. Li L, Di X, Zhang S, Kan Q, Liu H, Lu T, et al. Large amino acid transporter 1 mediated glutamate modified docetaxel-loaded liposomes for glioma targeting. Colloids Surf B Biointerfaces. 2016;141:260-7.

24. Machová E, O'Regan S, Newcombe J, Meunier F-M, Prentice J, Dove R, et al. Detection of choline transporter-like 1 protein CTL1 in neuroblastoma X glioma cells and in the CNS, and its role in choline uptake. J Neurochem. 2009;1 10(4):1297-309.

25. Azzalin A, Nato G, Parmigiani E, Garello F, Buffo A, Magrassi L. Inhibitors of GLUT/SLC2A Enhance the Action of BCNU and Temozolomide against High-Grade Gliomas. Neoplasia. 2017;19(4):364-73.

26. Miranda-Gonçalves V, Bezerra F, Costa-Almeida R, Freitas-Cunha M, Soares $\mathrm{R}$, Martinho $\mathrm{O}$, et al. Monocarboxylate transporter 1 is a key player in glioma-endothelial cell crosstalk. Mol Carcinog. 2017;56(12):2630-42.

27. Sontheimer H. An Unexpected Role for lon Channels in Brain Tumor Metastasis. Exp Biol Med (Maywood). 2008;233(7):779-91.

28. Thompson EG, Sontheimer $\mathrm{H}$. A role for ion channels in perivascular glioma invasion. Eur Biophys J. 2016;45(7):635-48.

29. Vaishali MP, Satya PG. Studies on Chloride Channels and their Modulators. Curr Top Med Chem. 2016;16(16):1862-76.

30. Jentsch TJ, Pusch M. CLC Chloride Channels and Transporters: Structure, Function, Physiology, and Disease. Physiol Rev. 2018;98(3):1493-590.

31. Cohen G, Burks SR, Frank JA. Chlorotoxin-A Multimodal Imaging Platform for Targeting Glioma Tumors. Toxins (Basel). 2018;10(12):496.

32. Stephen ZR, Chiarelli PA, Revia RA, Wang K, Kievit F, Dayringer C, et al. Time-Resolved MRI Assessment of Convection-Enhanced Delivery by Targeted and Nontargeted Nanoparticles in a Human Glioblastoma Mouse Model. Cancer Res. 2019;79(18):4776-86.

33. Formicola B, Dal Magro R, Montefusco-Pereira CV, Lehr C-M, Koch M, Russo $L$, et al. The synergistic effect of chlorotoxin-mApoE in boosting drug-loaded liposomes across the BBB. J Nanobiotechnology. 2019;17(1):115

34. Patil R, Galstyan A, Sun T, Shatalova ES, Butte P, Mamelak AN, et al. Polymalic acid chlorotoxin nanoconjugate for near-infrared fluorescence guided resection of glioblastoma multiforme. Biomaterials. 2019:206:146-59.
35. Mamelak AN, Rosenfeld S, Bucholz R, Raubitschek A, Nabors LB, Fiveash $J B$, et al. Phase I Single-Dose Study of Intracavitary-Administered lodine131-TM-601 in Adults With Recurrent High-Grade Glioma. J Clin Oncol. 2006;24(22):3644-50.

36. Patil CG, Walker DG, Miller DM, Butte P, Morrison B, Kittle DS, et al. Phase 1 Safety, Pharmacokinetics, and Fluorescence Imaging Study of Tozuleristide (BLZ-100) in Adults With Newly Diagnosed or Recurrent Gliomas. Neurosurgery. 2019;85(4):E641-9.

37. Lingzhou Z, Xiangyang S, Jinhua Z. Chlorotoxin-Conjugated Nanoparticles for Targeted Imaging and Therapy of Glioma. Curr Top Med Chem. 2015;15(13):1196-208.

38. Khanyile S, Masamba P, Oyinloye BE, Mbatha LS, Kappo AP. Current Biochemical Applications and Future Prospects of Chlorotoxin in Cancer Diagnostics and Therapeutics. Adv Pharm Bull. 2019;9(4):510-20.

39. Gonawala S, Ali MM. Application of Dendrimer-based Nanoparticles in Glioma Imaging. J Nanomed Nanotechnol. 2017;8(3):444.

40. Fana M, Gallien J, Srinageshwar B, Dunbar GL, Rossignol J. PAMAM Dendrimer Nanomolecules Utilized as Drug Delivery Systems for Potential Treatment of Glioblastoma: A Systematic Review. Int J Nanomedicine. 2020;15:2789-808.

41. Zhao L, Zhu J, Cheng Y, Xiong Z, Tang Y, Guo L, et al. Chlorotoxin-Conjugated Multifunctional Dendrimers Labeled with Radionuclide ${ }^{131}$ | for Single Photon Emission Computed Tomography Imaging and Radiotherapy of Gliomas. ACS Appl Mater Interfaces. 2015;7(35):19798-808.

42. Zhao L, Li Y, Zhu J, Sun N, Song N, Xing Y, et al. Chlorotoxin peptide-functionalized polyethylenimine-entrapped gold nanoparticles for glioma SPECT/CT imaging and radionuclide therapy. J Nanobiotechnology. 2019;17(1):30

43. Li X, Xiong Z, Xu X, Luo Y, Peng C, Shen M, et al. ${ }^{99 \mathrm{~m}} \mathrm{Tc}$-Labeled Multifunctional Low-Generation Dendrimer-Entrapped Gold Nanoparticles for Targeted SPECT/CT Dual-Mode Imaging of Tumors. ACS Appl Mater Interfaces. 2016;8(31):19883-91.

44. Xu X, Zhao L, Li X, Wang P, Zhao J, Shi X, et al. Targeted tumor SPECT/ $\mathrm{CT}$ dual mode imaging using multifunctional RGD-modified low generation dendrimer-entrapped gold nanoparticles. Biomater Sci. 2017;5(12):2393-7.

45. Zhou B, Zhao L, Shen M, Zhao J, Shi X. A multifunctional polyethylenimine-based nanoplatform for targeted anticancer drug delivery to tumors in vivo. J Mater Chem B. 2017;5(8):1542-50.

46. Zou Y, Li D, Wang Y, Ouyang Z, Peng Y, Tomás H, et al. Polyethylenimine Nanogels Incorporated with Ultrasmall Iron Oxide Nanoparticles and Doxorubicin for MR Imaging-Guided Chemotherapy of Tumors. Bioconjug Chem. 2020;31(3):907-15.

47. Chen C, Zhou B, Zhu X, Shen M, Shi X. Branched polyethyleneimine modified with hyaluronic acid via a PEG spacer for targeted anticancer drug delivery. RSC Adv. 2016;6(11):9232-9.

48. Zhu J, Wang G, Alves CS, Tomás H, Xiong Z, Shen M, et al. Multifunctional Dendrimer-Entrapped Gold Nanoparticles Conjugated with Doxorubicin for pH-Responsive Drug Delivery and Targeted Computed Tomography Imaging. Langmuir. 2018;34(41):12428-35.

49. Zhao L, Wen S, Zhu M, Li D, Xing Y, Shen M, et al. ${ }^{99 \mathrm{~m}}$ Tc-labelled multifunctional polyethylenimine-entrapped gold nanoparticles for dual mode SPECT and CT imaging. Artif Cells Nanomed Biotechnol. 2018;46(sup 1):488-98.

50. Zhou B, Wang R, Chen F, Zhao L, Wang P, Li X, et al. ${ }^{99 m} \mathrm{Tc}$-Labeled RGDPolyethylenimine Conjugates with Entrapped Gold Nanoparticles in the Cavities for Dual-Mode SPECT/CT Imaging of Hepatic Carcinoma. ACS Appl Mater Interfaces. 2018;10(7):6146-54

\section{Publisher's Note}

Springer Nature remains neutral with regard to jurisdictional claims in published maps and institutional affiliations. 